\title{
¿TRADICIÓN MOVIMENTISTA? ACERCA DE LAS RELACIONES DE CONTINUIDAD Y RUPTURA DE LOS MOVIMIENTOS YERBATEROS DE MISIONES
}

Social movement traditions? About the relationships of continuity and disruption at yerba mate movements in the province of Misiones, Argentina

\section{Delia C. Ramírez}

\section{Resumen}

En el presente texto se propone reflexionar sobre cuestiones referidas a los conflictos y movimientos agrarios del sector yerbatero de Misiones a partir de material empírico recolectado entre los años 2003 y 2005, desde herramientas proporcionadas por la perspectiva de la Antropología cognitiva y simbólica. Al mismo tiempo, buscamos complementar esta orientación con miradas provenientes de la Antropología política, rural, los enfoques sociológicos y estudios sobre acción colectiva.

El objetivo fundamental del trabajo apunta a indagar acerca de las relaciones de continuidad y discontinuidad, tradición y ruptura de esquemas culturales involucrados en el proceso de aparición de movimientos sociales yerbateros de la provincia de Misiones. Al mismo tiempo nos preguntamos por el sistema de clasificaciones de los actores sociales que participaron del Tractorazo de 2002 y las potencialidades analíticas y políticas de dichos términos empíricos.

$$
<\text { Movimientos sociales }><\text { Tradición }><\text { Yerba mate }><\text { Misiones }>
$$

\begin{abstract}
This text analyzes the conflicts and agrarian movements related to the yerba mate sector in the Province of Misiones from empirical material collected between 2003 and 2005 by using tools from the fields of cognitive and symbolic anthropology, enhanced with contributions from political and rural anthropology, sociological approaches and studies on collective action.

The main purpose of this study is to inquire about the relationships of continuity and discontinuity, tradition and disruption of cultural patterns involved in the emergence of social movements in the yerba mate sector in the province of Misiones. Furthermore, we look into the classification system of the social actors who participated in the 2002 protest called Tractorazo and the analytical and political potentialities of such empirical terms.
\end{abstract}

$$
<\text { Social movements }><\text { Traditions }><\text { Mate }><\text { Misiones }>
$$




\section{Introducción}

El presente texto se propone indagar acerca de las relaciones de continuidad y discontinuidad, tradición y ruptura, de esquemas culturales involucrados en el proceso de aparición de movimientos sociales yerbateros de la provincia de Misiones. Así, nos aproximamos a un problema sumamente complejo: estos conceptos pueden rastrearse como condiciones objetivas y subjetivas.

Cuando nos enmarcamos en la dimensión de las condiciones objetivas, hacemos referencia a un tiempo largo, a una construcción histórica, político-institucional y económica. En cambio, la dimensión subjetiva apunta a considerar la producción de representaciones sociales, categorías y clasificaciones en el nivel de los actores. En este texto proponemos pensar el concepto de tradición movimentista con el objeto de aproximarnos a un análisis de los movimientos yerbateros que involucre ambas dimensiones y niveles de análisis.

Para la reflexión se retoma el Tractorazo yerbatero de 2002, ocurrido en la capital misionera, Posadas, como caso paradigmático que invita a repensar el cambio en el mapa organizacional del complejo yerbatero. Se recurre a herramientas proporcionadas por la teoría de la acción colectiva, comprendiendo este concepto como el producto de "intenciones, recursos y límites, una orientación intencional construida mediante relaciones sociales desarrolladas en un sistema de oportunidad y obligaciones" (Melucci, 1994: 157). En esta dirección, entendemos que son los actores los que producen las acciones colectivas al ser capaces de definirse a sí mismos y, al mismo tiempo, de definir sus relaciones con el ambiente.

En relación con la dimensión subjetiva recurrimos a herramientas de la perspectiva de la antropología cognitiva y simbólica para reconstruir y aproximarnos al sistema de clasificaciones de los colonos que participaron del Tractorazo de 2002. Consideramos que este acontecimiento permitió visibilizar heterogeneidades culturales y desigualdades sociales dentro del sector.

En la primera parte del texto se realiza un breve recorrido por los procesos que afectaron a la conformación actual del complejo yerbatero. En la segunda, nos abocamos a los sucesos relativos al Tractorazo de 2002, en dicho apartado se describe el contexto de esta protesta. Seguidamente, se analizan algunos conceptos y categorías empíricas que forman parte del sistema de clasificaciones de los actores que participaron de la protesta en el marco de las organizaciones agrarias. Luego nos aproximamos al concepto de tradición movimentista como una propuesta para pensar en las relaciones de continuidad y ruptura dentro del complejo yerbatero. Finalmente, en la conclusión retomamos las cuestiones expuestas con el objeto de plantear preguntas más amplias que exceden los propósitos y las posibilidades del presente artículo.

Si bien este texto no es más que una primera aproximación al tema, rescata cuestiones que se presentan como relevantes para un abordaje de la cuestión yerbatera que aportan datos para pensar en una historia agraria de Misiones a partir de relaciones de conflicto y antagonismo. 


\section{Procesos recientes en el complejo yerbatero}

Misiones se caracteriza por la importancia de las actividades agrícolas y agroindustriales. La yerba mate es un cultivo fundamental dentro de este territorio; su importancia es económica, social, cultural y también política. La yerba mate (Ilex Paraguayriensis) data de la época prehispánica y con el tiempo se convirtió en una producción organizada hasta expandirse, con vistas al mercado nacional, a principios de siglo XX.

Aun con el avance de la modernización, la yerba continúa siendo un producto muy importante para Misiones, pues representa cerca del 50\% del PIB agropecuario y el $25 \%$ del industrial. Estas cifras sólo fueron igualadas en los últimos años por la industria celulósica papelera y también por la agroforestal (Rosenfeld y Martínez, 2003).

Misiones cuenta con el 90\% de la producción nacional de la yerba mate, el 10\% restante pertenece a la zona apta para el cultivo de la provincia de Corrientes. La yerba se adapta a los suelos rojos profundos, soporta elevados grados de acidez y requiere un clima cálido y húmedo de tipo subtropical o tropical. Esto ha limitado su expansión a otras zonas del país. La producción de yerba ocupa, a pesar de los avances de la modernización tecnológica, un importante porcentaje de la mano de obra agraria e industrial de Misiones. El destino de la producción es fundamentalmente el mercado interno, con una exportación variable de alrededor del 10\% de la producción (Rosenfeld y Martínez, 2003).

Gabriel Manzi (1999) describe las etapas de la actividad productiva de la yerba mate. En primer lugar nombra el cultivo y la cosecha, actividad agraria usualmente no mecanizada de la que depende, en muchos aspectos, la economía global de la yerba. Seguidamente este autor desarrolla la etapa de elaboración primaria, de la hoja cosechada que se cumple en los secaderos. Por último, se realiza el acondicionamiento para el consumo, es decir, los molinos toman la yerba mate canchada y estacionada que proviene de la elaboración primaria. Este es el proceso final y puede llamarse etapa industrial.

Entre 1930 y 1935 se produjeron las primeras crisis de superproducción. Para evitar una nueva crisis, en 1936 se institucionalizó el control de la producción y la comercialización de la actividad mediante la creación de la Comisión Reguladora de la Yerba Mate, CRYM (Ley N ${ }^{\circ} 12.236$, septiembre de 1935). La misma intervino sobre la producción y estabilizó la actividad aunque limitó el crecimiento (Manzi, 1999).

Esta comisión reguladora tenía atribuciones para prohibir/autorizar nuevas plantaciones y establecer cupos de cosecha. Estuvo vigente por más de 50 años ${ }^{1}$.

Las crisis de superproducción produjeron caídas de los precios y por ello por varios años se prohibieron los nuevos cultivos hasta que en la década de 1980 se originó una baja en la oferta y un alza en los precios (Gortari, 2002). Los sucesos relativos a la cuestión yerbatera relatados dieron un vuelco inesperado con las medidas de desregulación impulsadas por el gobierno nacional en la década de 1990. Las mismas repercutieron

${ }^{1}$ Para más información sobre la CRYM se recomienda la lectura de las producciones académicas de la historiadora económica María Victoria Magán. 
directamente sobre el sector de la producción yerbatera y generaron consecuencias nefastas para sus actores.

El nuevo régimen de acumulación forjado por la política neoliberal de Carlos Menem (1989-1999) y la "desregulación económica", que incentivó un proceso de "retirada" del Estado de las economías locales y productivas, propiciaron la expulsión de miles de pequeños productores y trabajadores del campo como resultado de transformaciones estructurales, y elevaron los índices de pobreza rural a cifras sin precedentes.

Misiones no estuvo exenta de estos problemas que afectaron al agro argentino, las estadísticas del INDEC la presentan como una de las provincias con más población residente en el campo y con mayor cantidad de explotaciones agropecuarias. No obstante, si bien los datos del Censo Nacional Agropecuario de 1988 y 2002 registran una tendencia a la disminución de las explotaciones $(2,13 \%)$, la cifra es muy inferior a lo sucedido a nivel nacional, donde el número de explotaciones descendieron en un 20,8\%. En tanto, los datos del Censo Nacional de Población, Hogares y Viviendas de 1991 y 2001 muestran que la población rural en Misiones cayó en un 3,39\%, tendencia que se condice con lo sucedido a nivel nacional, donde la población rural nacional disminuyó en un 8,4\%.

No obstante, los datos del CNA de 2002, muestran que en Misiones los pequeños y medianos productores agropecuarios continúan conformando el grupo más numeroso, pues el 52,7\% del total de las explotaciones se ubica en los estratos de hasta 25 hectáreas. Las unidades productivas que tienen más de 25 y hasta 100 hectáreas representan el $40 \%$ del total de explotaciones. En consecuencia, si sumamos ambos grupos arribamos al $92 \%$ de las explotaciones provinciales. De éstas, más del 50\% están dedicadas a la yerba mate. Este cultivo ocupa un gran número de mano de obra asalariada y es una de las actividades industriales más importantes de la provincia.

En el complejo yerbatero se inició un proceso de concentración productiva que favoreció a empresarios y grandes industrias posicionadas en el mercado y, a la vez, un proceso de descapitalización y empobrecimiento de pequeños y medianos productores, cooperativas, pequeños secaderos y obreros rurales de la yerba mate, los denominados tareferos.

En el marco de una metamorfosis de la estructura económica, política y social del complejo yerbatero se desarrolló la movilización de pequeños y medianos productores. Esto coincidió con un ciclo de protestas que se desarrolló a nivel nacional frente a una coyuntura marcada por el desempleo, la desigualdad social y una crisis políticoinstitucional.

\section{De las chacras a la plaza: el Tractorazo yerbatero de 2002}

Entre mayo y julio de 2002 se desarrolló el llamado Tractorazo en la plaza central de Posadas, capital de Misiones. Esta protesta fue organizada por una "coordinadora" constituida por diferentes organizaciones productivas, empresariales, sociales, sindicales, religiosas y profesionales de la provincia, que reclamaba la revisión de políticas de Estado 
relacionadas con la producción, la industria, la salud, la educación, el comercio, entre otras cuestiones. Sin embargo, el principal reclamo que se destacó por sobre el resto, por la modalidad y los repertorios de protesta, fue el de los productores yerbateros.

El 29 de mayo de 2002 los yerbateros de distintas localidades de Misiones llegaron a Posadas con el apoyo de diversos sectores de la sociedad posadeña y se instalaron en la plaza 9 de Julio por tiempo indeterminado hasta que consiguieran una respuesta concreta a sus reclamos. De este modo, trabajadores agrarios, productores y tareferos, muchos de ellos acompañados por sus familias, se hicieron "visibles" en el escenario político de la provincia, a través de su estadía en la plaza -principal metodología de protesta-, actos masivos, escraches, marchas y movilizaciones.

El Tractorazo de 2002 duró 53 días y atravesó por diferentes etapas que se vieron expresadas en las modalidades de acción colectiva adoptadas por sus participantes. Se debe tener en cuenta que el mismo contexto conflictivo nacional favoreció a la organización de la acción colectiva y a la expresión de protesta. Para algunos, este acontecimiento marcó un hito histórico en la política agraria de Misiones, pues la protesta finalizó con la creación del Instituto Nacional de la Yerba Mate (INYM), un ente regulador de la economía yerbatera; para otros, permitió la comunicación de un sector de la población excluido en las chacras del interior de la provincia sin afectar a la opinión pública o a la agenda de los medios, pues antes de esta protesta la problemática de los sectores yerbateros más vulnerables no se constituía como "noticia".

Es relevante destacar que el ciclo de protestas iniciado en el 2001 se caracterizó fundamentalmente por la ausencia en los roles protagónicos de los gremios y asociaciones agrarias tradicionales: el Movimiento Agrario Misionero (MAM), la Federación de Cooperativas Agrícolas de Misiones (FEDECOOP), la Asociación Rural de Yerbateros Argentinos (ARYA) y el Centro Agrario Yerbatero Argentino (CAYA). En este contexto se dio la aparición de nuevos actores en la escena pública, quienes canalizaron las demandas de los pequeños y medianos yerbateros. De estas entidades es el MAM quien posee una sólida trayectoria de acción colectiva consolidada en los años '70. Con el regreso de la democracia el MAM continuó representando a pequeños y medianos productores, pero su rol y su accionar se modificaron a partir de una activa participación en programas sociales en los años ' 90.

La creación del INYM en 2002, luego de presiones continuas y cada vez más combativas, no significó el fin de las protestas, ya que los productores de las organizaciones emergentes, además de participar en la negociación de los precios, continuaron realizando acciones colectivas que apuntaron, según sus testimonios, a la consecución de un "precio justo" para la materia prima. Los dirigentes agrarios, en su mayoría miembros de la Asociación de productores de Misiones (APAM), en frecuentes ocasiones expresaron en declaraciones públicas su desagrado por las gestiones del INYM y también realizaron "escraches" para manifestar repudio por ciertos directores de este Instituto. 
Ramírez. Continuidad y ruptura en los movimientos yerbateros de Misiones.

\section{Primera aproximación al sistema de clasificaciones de los actores participantes}

A partir de la breve reseña antes realizada, es posible afirmar que el Tractorazo de 2002 permitió visibilizar diferentes cuestiones. Por un lado, la situación de pobreza rural, desconocida para un amplio sector de la opinión pública de los centros urbanos; por otro, el surgimiento de movimientos sociales y líderes yerbateros que se convirtieron en representantes de ese colectivo heterogéneo y desigual.

Además, el Tractorazo puso en evidencia la fragmentación del sector de la producción primaria de la yerba mate en Misiones, lo que se manifestó en la construcción de antagonismos y sistemas de oposiciones que aparecen en los relatos de los actores participantes del Tractorazo. Frecuentemente, ellos producen clasificaciones del tipo: "los yerbateros del norte son más pobres", "los de la ruta 12 son pequeños empresarios", "los productores más pobres están agrupados en APAM"; y sistemas de clasificaciones o categorías antagónicas "cooperativizados"/"no cooperativizados", productores de la zona "centro"/ "norte"/ "sur", "productores de la ruta 12"/ "productores de la ruta14".

El dirigente de APAM, HS, reconoció una diversidad y heterogeneidad dentro del sector yerbatero:

"Es muy heterogéneo, si tenemos en cuenta las corrientes migratorias en la provincia de Misiones. Tenemos a su vez diferencias entre los que están en la costa del río Paraná y los que están en la costa del río Uruguay. Los que están cooperativizados, los que pertenecen a cooperativas o no, también hay diferencias desde el punto de vista de su fe. Es muy distinto un católico, un luterano, de un sabatista por ejemplo, ¿no? En su forma de producir y de pensar".

A y R, una pareja de medianos productores de Apóstoles $^{2}$, realizaron una clasificación sumamente interesante, en la que se destaca no sólo la heterogeneidad cultural entre los productores sino la desigualdad social que reconocieron a partir del Tractorazo de 2002:

\section{"¿Qué recuerda de esa protesta?}

R - Que vimos gente más pobre de lo que somos nosotros en la zona sur. Había gente que daba lástima ver.

A - Lo que más me impresionó fue nuestra zona comparando con gente del norte que me dio lastima de ver. Y digo con mucha lástima porque vi gente que yo de una forma me satisfacía de la forma en que yo estaba porque realmente veía cosas peores. Yo veía personas peores a mi situación.

\footnotetext{
${ }^{2}$ Apóstoles es una localidad que se encuentra al sur de la provincia de Misiones y limita con Posadas. La yerba es allí un cultivo fundamental, de gran importancia productiva. El gremio más combativo de la zona se denomina APAZUR. Por otra parte, en Apóstoles radican industriales de la yerba mate de gran poder adquisitivo e incluso posicionados en el poder político. Es el caso de Ramón Puerta, dos veces gobernador de la provincia por el Partido Justicialista.
} 


\section{¿Ustedes no conocían antes la pobreza de esa gente?}

$\mathbf{R}$ - No realmente se comentaba pero nunca he visto tan a fondo. Porque a veces, porque a veces los comentarios viste son otra cosa.

A - Nunca he visto, nunca he visto, a mi me parecía en ese momento que nuestra zona era más pudiente, era mejor paga, de un mejor pasar que la gente del centro y el norte. A mí me impresionaba ver mucha gente adulta, madura ya vieja, jóvenes también, pero se notaba mucho la diferencia".

Por su parte, el dirigente de ARYA y FEDECOOP, SP, diferenció a los productores "cooperativistas" de los "no cooperativistas" de la siguiente manera:

"Entonces yo veía es que el más fogoso defensor de los paros y piquetes eran quienes no pertenecían a cooperativas. La gente que está en las cooperativas ya encausa su lucha a través de una empresa cooperativa y votando y manejando su empresa, entonces se organiza inteligentemente y buscan mejorar su precio. Porque una cooperativa, si tiene su producto en góndola puede manejar mejor el precio que si vende la materia prima. Y ahí el precio de la ganancia lo pone el que vende el paquete. Y un dirigente cooperativo está en otros problemas de compra y venta y no tenés tiempo para salir a cortar una ruta. Entonces son distintos liderazgos. Están los líderes empresarios productivos y están los líderes carismáticos filosóficos a secas que hasta para cortar una ruta produjeron un problema para los productores yerbateros cooperativistas, porque cuando cortaron la ruta yo tenía que sacar ese día un equipo con yerba de productores y ellos dijeron no, acá no sale nadie Yo decía córtenle la ruta a otro molino, no a una colonia de productores de Eldorado que ya supieron organizarse, porque no es fácil organizarse en una cooperativa".

En tanto, PZ, dirigente de APAZUR realizó la misma clasificación pero en un sentido opuesto.

"Y voy a decir algo que les molesta a las cooperativas cuando yo digo, pero las cooperativas son las que sujetan el precio y no permiten que el precio sea rentable para el productor. Si las cooperativas tomaran el rol que tienen que tomar, en este momento la hoja verde estaría como 37 o 38 centavos. Porque hoy yo le dije ¿eh? La culpa de que hoy no tenemos precio fijo, las culpables son las cooperativas. Te dije hoy. Las cooperativas que están por ARYA y FEDECOP. ¿Por qué? porque tienen miedo de la extorsión del gobierno. Entonces eso hay que quebrar todavía". 
Ramírez. Continuidad y ruptura en los movimientos yerbateros de Misiones.

Además, SP diferenció a los productores de la ruta 12 de los de la ruta 14 .

"Pero hay una diferencia en el tipo de productor, es muy distinto el productor de la zona de la ruta 14 que el de la ruta 12. El de la ruta 12 era un empresario que venía de Europa y que logró hacer su establecimiento y todo, eran productores que venían ya con ideas de empresa, y el de la ruta 14 empezaron a plantar yerba como un complemento. Tenían porotos, maíz y una hectárea de yerba, eran pequeñas parcelas y después hubo también grandes empresarios que anexaron terrenos, plantaron yerba y se hicieron grandes empresarios, pero eso está más en Apóstoles. Ya en el resto de la ruta 14 son todos pequeñísimos productores. Y en la ruta 12 tenés muchas empresas yerbateras, esa sería la diferencia, en la ruta 14 hay pequeños productores salvo Apóstoles, el sur, Oberá, Apóstoles, y en la ruta 12 de norte a sur tenés empresas por todos lados".

PZ, por su parte, realizó una clasificación que si bien se basa en un eje territorial es diferente a la enunciada por SP: “[...] la zona centro es la más sufrida. Es la que en peor estado están sus yerbales, es la que peor está en sus casas, es la que más castigada fue porque no se supo defender. Porque acá aparece otra cosa... la organización que está en el centro, el MAM... [...]" A la vez, este proceso de diferenciación y clasificación en relación a la ubicación espacial y geográfica de los productores tiene una vinculación con las organizaciones que tienen intervención en lo político. Es decir, definen políticamente a las organizaciones: "Hay gente que está organizada totalmente pero son gente que tiene poder. No conviven con el colono. APAZUR o APAM, vivimos con el productor... no con el empresario... vivimos con el productor.” (PZ, dirigente de APAZUR)

\section{¿Continuidad o ruptura? Sobre el concepto de tradición movimentista}

Los trabajos académicos sobre la historia de las luchas de los productores agrarios de Misiones se han centrado principalmente en: a) la llamada masacre de Oberá, ocurrida en 1936, y b) en las organizaciones agrarias de la década de 1970 y su posterior represión a partir de la dictadura instaurada en el país entre 1976 y 1983.

El antropólogo Leopoldo Bartolomé, en una investigación que data de 1982, indagó sobre la estructura agraria de la época e identificó que en su mayoría los adherentes del MAM eran medianos y pequeños productores y provenían de localidades cercanas al trazado de la ruta nacional $\mathrm{N}^{\mathrm{o}}$ 14. Trabajó sobre los factores culturales y económicos que favorecieron la conformación del MAM y las prácticas de acción colectiva. El MAM -que desde su surgimiento asumió la representación de los pequeños y medianos productores- mostró su capacidad movilizadora a través de reiteradas huelgas, marchas y concentraciones multitudinarias. La Asociación de Movimientos de Agricultores (AMA) y las Ligas Agrarias de Misiones (LAM), ambos desprendimientos del MAM, aunque no prosperaron, fueron parte del mapa organizacional hasta 1975. 
Diversos autores se han preguntado cómo fue posible una organización de estas dimensiones entre productores sin tradición de lucha, sobre todo en las ligas de nordeste y el MAM en Misiones. Diferenciándonos de estos planteos, nos enfocamos en las organizaciones agrarias surgidas luego de 2001. En esta dirección arriesgamos que, así como Maristella Svampa (2005) invita a pensar en los derechos de los trabajadores de la sociedad industrial como telón de fondo para la movilización de los desocupados, los denominados movimientos piqueteros, se podría considerar la influencia de la trayectoria del MAM y de las Ligas Agrarias del Nordeste en la conformación de una tradición movimentista como experiencia capitalizada en la acción de las organizaciones emergentes. Por lo tanto, llamamos tradición movimentista a las trayectorias de lucha de las organizaciones de los '70, interrumpidas por el golpe de Estado de 1976.

Esta es apenas una hipótesis arriesgada y prematura que surge de algunos relatos de los productores entrevistados que narran sobre su experiencia y la comprensión de esta experiencia. Veamos como ejemplo el testimonio de un dirigente de APAM:

"Esto fue dificilísimo porque había toda una historia previa, era mala palabra, mucho miedo, y fijate que las tres protestas grandes entre comillas, surgen en la zona centro, más o menos en las mismas colonias, entonces quién no tuvo un padre, un abuelo que no estuvo metido en una represión, por pedir justicia. Entonces era muy difícil, poder sacarle a la gente a que salga a la ruta a protestar".

En otra oportunidad el mismo dirigente señaló:

"Recordemos que en la década de 1930, 1936, 15 de marzo, fue la masacre de Oberá donde productores de tabaco que querían un mejor precio y también pedían que no se les cobre un impuesto para la plantación de yerba mate y pedían la mensura de las tierras fueron esperados por el poder político y económico en el pueblo de Oberá y los hombres fueron matados, las mujeres, fue algo muy triste, ¿no es cierto? Así que se repliegan los colonos a sus chacras, pasan muchos años y a fines del ' 60 y principios del $` 70$ aparecen las ligas agrarias misioneras, el MAM, también sufre represión, muerte, sangre, así que fue algo es bastante difícil decirles a los colonos que tenían que salir a luchar por su dignidad".

Como se mencionó anteriormente, en la actualidad el rol del MAM se ha modificado a partir de su intervención en políticas públicas y la creación de las Ferias Francas $^{3}$, mientras que son las nuevas organizaciones las que intervienen en acciones

\footnotetext{
${ }^{3}$ Las Ferias Francas son emprendimientos de autogestión que tienen lugar en espacios públicos de pueblos o ciudades. Estos emprendimientos de comercialización de productos de la chacra fueron desarrollados por los pequeños productores de Misiones como estrategia de supervivencia. Al respecto se puede leer el texto
} 
Ramírez. Continuidad y ruptura en los movimientos yerbateros de Misiones.

más combativas. Un supuesto que merecería un abordaje en profundidad es que los productores que participan en APAM y en otras organizaciones emergentes no pertenecen, y aparentemente no pertenecieron, a la estructura del MAM.

El estudio de este nuevo actor colectivo, que hemos denominado organizaciones emergentes, su posición en la nueva configuración del mapa organizacional gremial y en la estructura productiva del complejo yerbatero, así como la relación de las mismas en contextos contemporáneos, son asignaturas pendientes. De todos modos, el mismo concepto de tradición movimentista connota la introducción de la dimensión cultural y aspectos cognitivos y simbólicos en el análisis.

Mayer Zald (1999) plantea que las ideas y factores culturales son cruciales a la hora de comprender la movilización de los actores participantes y también la estructuración de la oportunidad política como los marcos estratégicos en los que se encuadran las injusticias. Aquí el concepto de injusticia no debe comprenderse como la persecución de un fin, sino como un proceso de interpretación constante por parte de los actores que intervienen en la construcción de repertorios de argumentos y los marcos en los cuales se encuadran esos argumentos. Para Zald, "símbolos, marcos e ideologías se crean y se transforman en los procesos de oposición y protesta" (1999: 371).

Por otra parte, la misma metodología de protesta que utilizaron las organizaciones emergentes a partir de 2001 plantea interrogantes acerca de los cambios en las formas de las acciones colectivas. El concepto de repertorios de acción colectiva de Charles Tilly resulta iluminador en este sentido. Tilly sostiene que quienes participan en los enfrentamientos cuentan en cada momento con un repertorio bien definido, "adquirido por ellos a través de un proceso de aprendizaje, dentro del cual están permitidas ligeras variaciones" (Pérez Ledesma, 1994: 65).

La realización de las prácticas de protesta de Tractorazos (2001, 2002 y 2007) puede comprenderse como un cambio en la estrategia de acción y en los repertorios de protesta. Los productores se han desplazado del silencio de las chacras del interior de Misiones para hacerse visibles, exhibir así sus herramientas de trabajo y su pobreza en un espacio público de la capital provincial, en un espacio "de otros"4.

Cabe entonces preguntarse por los repertorios tradicionales, por los demás repertorios de acción que acompañaron al Tractorazo (cortes de ruta, escraches, asambleas, etc.) y las formas de socialización de esos repertorios, pues es sabido por la reproducción

de Pablo Lapegna (2005).

${ }^{4}$ Alberto Melucci (1994) considera que la acción tiene fases de latencia y visibilidad, lo cual permite pensar en la continuidad de una acción más allá de su expresión pública. Estos conceptos remiten a los contrastes entre la chacra y la ciudad, ya que mientras esta última, y más específicamente el espacio público de la plaza 9 de Julio, se presenta como la vidriera de los conflictos sociales, espacio de materialización y/o visualización de los actores silenciados por las políticas neoliberales, la chacra, y fundamentalmente las colonias como espacio de intercambio para la acción, son el lugar en el que se gestan estas apariciones o acciones públicas. Desde siempre se ha pensado en la chacra como el lugar en que "trabajan los colonos". Nuestra sospecha aquí es que el ciclo de protestas yerbateras que se inició en el 2001 ha repolitizado ambos territorios y con ello se reconfiguraron mapas cognitivos y representaciones sociales. 
de la prensa y la producción de textos académicos, que los Tractorazos se convirtieron en símbolo de lucha agraria en los años ' 90 , ya que en otras provincias se ha llevado a cabo la misma metodología de protesta.

En relación con los repertorios, se ha retomado el texto denominado "Yerba Mate: El 'Paro Verde' (Misiones, 4 de abril - 8 de mayo de 2000)" del sociólogo Víctor Rau $(2002)^{5}$ porque allí se describe la tradición de lucha de los sectores agrarios misioneros y se percibe en las huelgas del Paro Verde una continuidad en los repertorios de protesta que llevaron a cabo los actores del MAM en los años '70. Al respecto, Rau sostiene:
“[...] más allá de sus métodos de lucha y procedimientos de organización, la impronta legada por el funcionamiento provincial de la entidad lingüista contribuye a configurar otros importantes elementos que se actualizan en la amplia constelación de pautas de comportamiento y orientaciones para la acción tradicionalmente compartidas por estos agricultores" (Rau, 2002:3).

El trabajo de Rau relata la trayectoria de algunas de las nuevas organizaciones que surgen a fines de los años ' 90 y principios de 2000 , como APAZUR, y las primeras protestas realizadas por estas incipientes organizaciones. También reconstruye dinámicamente el mapa de actores que intervienen en el conflicto. Las organizaciones gremiales y las acciones colectivas aparecen en relación con las localidades productivas del interior de la provincia (Apóstoles, Jardín América, Oberá, Andresito, entre otras). Por lo tanto, este trabajo se presenta como la antesala de otra etapa de acciones colectivas posteriores que se dan a partir de 2001 con los Tractorazos; y aunque su foco de atención se centra específicamente en los obreros rurales, el artículo presenta discusiones que merecen ser retomadas en torno a la comprensión de una tradición movimentista que se pondría en juego en las acciones políticas contemporáneas y en las configuraciones políticas de los actores.

\section{Consideraciones finales}

Con este trabajo hemos realizado una primara aproximación -problematización- a un tema complejo. Conceptos como tradición, ruptura, continuidades y discontinuidades

\footnotetext{
${ }^{5} \mathrm{Al}$ observar la composición de los movilizados, el autor presenta una alianza de una pequeña burguesía rural y agrícola con el proletariado rural, lo cual define a la protesta como movimiento. Los cosecheros de yerba mate, sobre todo de Jardín América, asumieron como propias las demandas de sus empleadores en torno al precio de la materia prima. Aquí radica la novedad del acontecimiento resaltada en el texto. Esto se da, según Rau, por lo cambios en las modalidades de contratación "por cuadrilla" y la migración del campo a las áreas urbanas, más precisamente a barrios periféricos. Él considera que el traslado de los tareferos a las periferias urbanas ha sido una variable fundamental para su participación en las huelgas, sin embargo, no estamos seguros que esta misma hipótesis sea aplicable al caso de los pequeños y medianos productores. En esta dirección será imprescindible conocer quiénes son aquellos que integran las organizaciones emergentes, para de este modo indagar acerca de las relaciones de continuidad y ruptura con las estructuras sindicales tradicionales.
} 
pueden rastrearse como condiciones objetivas o subjetivas. Como ya se ha dicho, en el primer caso se hace referencia a una construcción histórica político-institucional y económica. En el segundo, hablamos de la producción de representaciones sociales, categorías y clasificaciones en el nivel de los actores.

A lo largo del texto hemos relacionado el relato analítico en ambos niveles o escalas, y en el futuro nos interesaría profundizar en las relaciones de continuidad y ruptura de las organizaciones emergentes a partir de lo que denominamos tradición movimentista.

Por otra parte, revisando la historia de los actores agrarios que fueron víctimas de la represión de la llamada masacre de Oberá de 1936, la trayectoria del MAM y las Ligas Agrarias y las luchas contemporáneas, vemos que el pedido de un "precio justo" y la asociación de esta consigna con la palabra "dignidad" aparece como una demanda histórica que se actualiza con las diferentes coyunturas. En este sentido, lo que varía es el significado de "precio justo": en determinadas circunstancias el reclamo apunta a la intervención del Estado, tal es el caso de la protesta de 2001; en el Tractorazo de 2002, significa creación del INYM; en 2007, la creación de un Mercado consignatario. Todo esto demuestra la activa participación de los actores en el proceso de definición de sus situaciones y en la presentación pública de sus demandas.

Indagar en cuestiones referidas a las relaciones de continuidades/ discontinuidades, tradición/ruptura no resulta simple porque ni la teoría general, ni los estudios sobre Misiones dan pistas seguras sobre dichos procesos que transitan los colectivos que dicen representar a los intereses del sector agrario. Desde los tiempos del MAM y las Ligas Agrarias al presente, han operado variables ligadas a lo ideológico y a lo cognitivo, pero también matrices que tienen que ver con cambios económicos, productivos, organizativos, sociales y comunicacionales, cuestiones que influyen en los procesos sociales.

Por otro lado, en el texto se han presentado algunas clasificaciones y sistemas de categorías antagónicas nativas que registramos entre los dirigentes de algunas organizaciones agrarias a partir del Tractorazo de 2002. Se espera a través del trabajo de campo y una revisión analítica más profunda, ver cuáles de estas clasificaciones merecen ser consideradas o si, de lo contrario, pueden proponerse nuevos conceptos que aporten a la comprensión del campo político del complejo yerbatero.

En otro orden de cosas, a partir del conflicto yerbatero, hemos reconstruido tramas de sentido relacionadas con diferenciaciones económicas sobre un eje territorial vinculadas a las organizaciones gremiales. Son los mismos productores que participaron de las protestas los que reconocen esas diferencias, visibles a partir del Tractorazo de 2001 y con más claridad en el Tractorazo de 2002.

A partir de lo expuesto nos hemos planteado los siguientes interrogantes: ¿cómo interviene la heterogeneidad de posiciones en el conflicto yerbatero?, ¿de qué modo se tramitan y negocian esas heterogeneidades? Para responderlos será necesario profundizar el análisis en las heterogeneidades y desigualdades entre los actores yerbateros y, específicamente, entre los actores movilizados, temas sustanciales en la trama política y económica del complejo yerbatero. 


\section{Referencias Bibliográfícas}

Bartolomé, Leopoldo, 1975, “Colonos, plantadores y agroindustrias. La explotación agrícola familiar en el sudeste de Misiones", Desarrollo Económico, Volumen 15, No 58, Posadas, 240-264.

Bartolomé, Leopoldo, 1982, "Base social e ideología en las movilizaciones agraristas en Misiones entre 1971 y 1975. Emergencia de un populismo agrario", Desarrollo Económico, № 85, Volumen 22 abril, junio.

Gortari Javier, 2002, "La yerba Mate: un rito guaraní de interés universal”, presentación a UNESCO, Secretaría de Cultura de la Nación.

Lapegna, Pablo, 2005, "Transformaciones y nuevas articulaciones agroalimentarias. Las ferias francas de la provincia de Misiones", en Giarraca, Norma y Teubal, Miguel (comps), El campo argentino en la encrucijada. Estrategias y resistencias sociales, ecos en la ciudad, Buenos Aires, Alianza Editorial.

Manzi, Gabriel, 1999, Desarrollo industrial de Misiones. Una óptica crítica para la discusión con miras a la integración regional, Posadas, Editorial Universitaria.

Melucci, 1994, "Asumir un compromiso: identidad y movilización en los movimientos sociales", en Zona Abierta, $\mathrm{N}^{\circ}$ 69, 153-178.

Pérez Ledesma, Manuel, 1994, "Cuando lleguen los días de la cólera (Movimientos sociales, teoría e historia)", en Zona Abierta, No 69, Madrid, 48-118

Ramírez, Delia, 2005, "De las chacras a la plaza: el Tractorazo del 2002 en Misiones", tesis de grado para Licenciatura en comunicación social (FHyCS, UNaM), directora: Dra: Gabriela Schiavoni.

Rau, Víctor, 2002, "Yerba Mate: El 'Paro Verde' (Misiones, 4 de abril - 8 de mayo de 2000)", en Realidad Económica, No 185, Buenos Aires, IADE, enero-febrero de 2002, 122-144.

Rosenfeld, Víctor y Martínez, Enrique,2003, "El conflicto yerbatero; un triunfo contra la desregulación en el agro. La Situación del sector yerbatero en Misiones y las nuevas formas de regulación". Terceras jornadas interdisciplinarias de estudios agrarios y agroindustriales, Posadas.

Svampa, Maristella, 2005, "La sociedad excluyente. La Argentina bajo el signo del neoliberalismo", Buenos Aires, Taurus.

Zald, Mayer, 1999, "Cultura, ideología y creación de marcos estratégicos” en D.Mc Adam, J. McCarthy y M.Zald, Movimientos sociales, perspectivas comparadas, España, Istmo.71-99.

\section{Fuentes:}

Diarios El Territorio y Primera Edición, 2001, 2002, Posadas, diversas ediciones de junio, julio y agosto.

Censo Nacional Agropecuario de 1988 y 2002, http://www.indec.mecon.an

Censo Nacional de Población, Hogares y Viviendas de 1991 y 2001 http://www.indec.mecon.an

\section{Entrevistas a:}

HS, dirigente de APAM, 29 de mayo de 2003 y 10 de abril de 2004, Posadas.

HS, dirigente de APAM, 10 de marzo de 2004, Posadas.

A y R, productores de Apóstoles, 3 de abril de 2004, Jardín América

SP, dirigente de ARYA y FEDECOOP, 5 de febrero de 2004, Eldorado.

PZ, dirigente de APAZUR, 3 de abril de 2004, Jardín América, Misiones. 